\title{
Exploration of prefabricated building system in housing construction
}

\author{
Neha Gupta1 ${ }^{1}$, Mohammad Arif Kamal 2,*, Tejwant Singh Brar
}

1 Shushant School of Art \& Architecture, Ansal University, Gurgaon, India.

2 Architecture Section, Aligarh Muslim University, Aligarh, India.

* Cor responding Author: architectarif@gmail.com

Received: 31-12-2020

Accepted: 04-02-2021

\begin{abstract}
The main purpose of this paper is to examine the development and current status of prefabrication techniques and their application in building construction and why its use is still limited in the housing sector in India and why prefabrication is not being used so far to provide affordable housing to all. Prefabrication is the practice of assembling components of a structure in factories, and then transporting the complete assemblies or sub-assemblies to the construction site where the structure is to be located. The important aspect is how much of a potential difference it can establish so that appropriate development can be implemented. This paper reviews the current prefabrication system scenario for housing in India. The paper begins with a brief introduction about different types of prefabrication system. Subsequent topics address the need of prefabrication and ethical dilemma of technology transfer for prefabricated building system in India. In this paper, a qualitative descriptive evaluation research method has been used. The research methodology comprises of case studies, visual observation and data collection. Finally, two case studies around the world have been presented to validate and illustrate the various modern trends and application of design and construction methods of prefabricated building system in housing.
\end{abstract}

Key words: Prefabrication, building, construction system, housing, India.

\section{Introduction}

The Prefabrication is defined as the assembly of buildings or their components at a place other than the building site. It is often referred by new term Modern Methods of Construction (MMC) in an order to reflect technical improvements in prefabrication, encompassing a range of on and off-site construction methods. The term 'modern methods of construction' covers a wide range of products, including everything from individual building components to entire factory-built structures and modules. The recently available are volumetric elements, such as fully fitted bathrooms or kitchens. The hotel sector has embraced these elements on a large scale. Emergence of a lot of factory-made cladding solutions using everything from traditional bricks to modern composites can be seen (Arieff and Burkhart, 2002).

The use of prefabrication can be useful to achieve results for the society's needs because the fast changing environment, industrialization, residential need and many other factors of transportation like bridges, towers, railways calls for fast settlement and requirement for buildings, offices and industries, hence prefabrication can be the solution for fast construction. The quality of construction will be much higher when components of housing are manufactured in a stable environment such as factory. This is especially true in India where, prefabrication had already become synonymous with modern and western construction methods. Materials are used more efficiently, safe from climatic damage, and can be reused. Because of these benefits, a general consensus in India is to move towards prefabricated building systems in housing. In this fast growing population country, it is necessary to have more residential with lesser cost and lesser time. Cost reduction can be made by several ways and one such way is to use prefabrication. To reduce the overall cost and greatly to reduce the construction time, 
prefabricated units are adopted. Prefabricated structure can also be one, the component member of which is precast, either in factories or in temporary plant, these precast members are transported to the site and then they are set into complete structure. Adopting any technology on large scale need to have a guaranteed market to fulfill its function and this cannot be achieved until the product is economical. Prefabrication has the capacity to establish a difference within the Indian context in economic, social and environmental terms.

The ultimate example of off-site manufacture is fully volumetric construction, in which buildings are compiled by attaching together a series of room or apartment modules that have been built, fitted out and finished in factories. Prefabrication technique is popularized for schools and hospitals, and has recently being used for the construction of affordable housing (Young et al., 2020).

\section{Types of prefabrication}

MMC is a broad category that includes a variety of building approaches including Off-Site Manufacturing (OSM). Whereas all OSM can be covered up under MMC, but not all MMC may be regarded as OSM. To explain this, there is range of categories (Arieff and Burkhart, 2002)

\subsection{Off-Site Manufacturing (OSM)-Volumetric}

Volumetric construction (also known as modular construction) includes the production of three dimensional units in factory conditions before transportation to the actual site. Units can be manufactured out of materials including steel, concrete and other materials. Modules can be brought to the site in a variety ranging from a basic structure to one with all internal and external finishes and services installed, all ready for assembly.

\subsection{Off-Site Manufacturing (OSM)-Panelized}

Flat panel units are produced in a factory and assembled on-site to produce building structure. Most common approach is the utilization of open panels which includes a structure only with external cladding, services and internal finishing on-site. More complex panels - typically referred as closed panels - includes more factory-based fabrication and can include skin materials. The panels can also include services, internal wall finishes and external claddings. The panelized system is more flexible than volumetric system and can provide variations in unit plan easily.

\subsection{Off-Site Manufacturing (OSM)-Hybrid}

A method - also referred to as semi-volumetric - it combines both panelized and volumetric approaches. Typically, volumetric units (sometimes referred to as 'Pods') are used for the highly services and more repeatable areas such as kitchens and bathrooms, with the remaining building completed by panels. This approach is basically used to provide flexibility on complex sites, because with both volumetric and panelized approaches the degree of factory-based fabrication can vary to a great extent.

\subsection{Off-Site Manufacturing (OSM)-Sub-Assemblies and Components}

This category includes factory built sub-assemblies or components in an otherwise traditionally built form. Incorporating the use of floor cassettes and precast concrete foundation assemblies, cladding systems, preformed service installations etc.

\subsection{Non- Off-Site Manufacturing (OSM) Based Systems}

These are systems that fall outside the category of 'Off-Site Manufactured' such as Insulated Concrete Formwork (ICF). Only systems which have independent third party approval will meet 
the requirements of the Technical Manual. The acceptability of these systems relies heavily on the quality procedures in place for the installation of the system on-site - in accordance with third party approval.

\section{Aim and objectives of the research}

The purpose of the study is to focus at the limited use of prefabrication in Housing Sector in India, mainly focusing on the potential impact it can have on meeting the ever increasing housing demands of increasing population of India. The aim of the study, to determine the factors needed for the successful use of prefabrication in the construction industry specifically housing sector. The objective of the study is to identify, examine and analyze the main problems that limit the use of prefabrication in housing sector in India and o determine why prefabrication has not been more widely adopted to provide higher quality product. The study shall also focus on why the prefabrication not being used so far to remove the ever increasing housing demands and why still manual construction is preferred over multi block prefabrication for multi storey buildings.

\section{Research methodology}

This diagram shows the systematic/ stage wise steps which form the theoretical framework to achieve the aim of the research/study. The given below methodology will help in framing the dissertation research in proper structure and help in analyzing the case studies from the factors obtained from a theoretical framework from the literature reviews.

\section{PREFABRICATION OF BUILDING SYSTEMS}

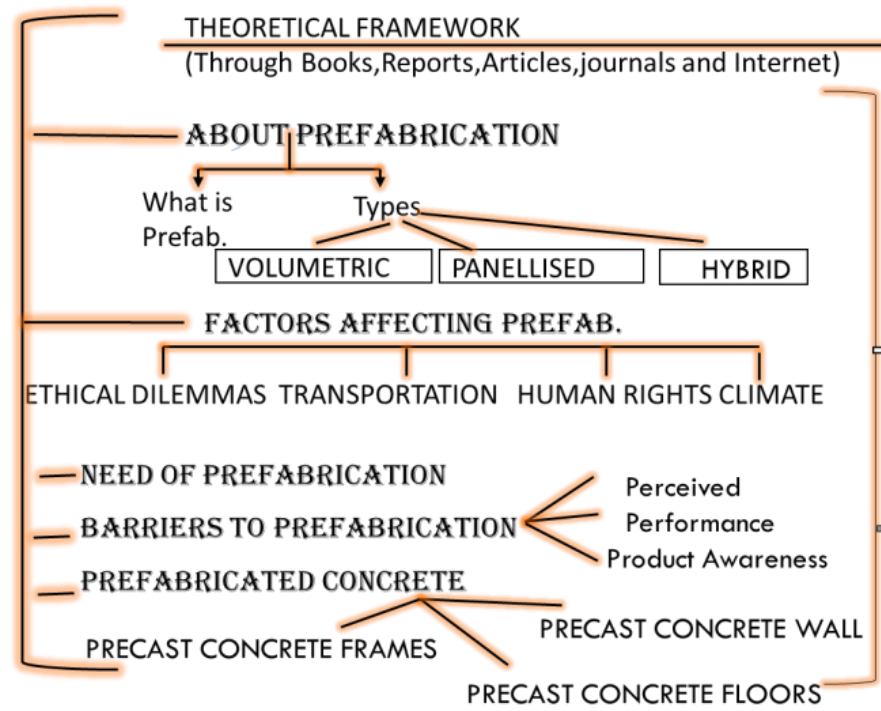

PRECAST CONCRETE FLOORS

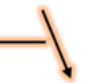

ANALYSIS

Certain questions will be answered:

Focus is at the limited use of prefabrication in

Housing Sector in India.

- main problems that limit the use of prefab.

- why the prefabrication not being used so far to remove the ever increasing housing demands

$\Rightarrow$ and to provide affordable housing.

- To find out why still manual construction is preffered over multi block prefabrication for multi storey buildings.

FROM CASE STUDIES:

$\Rightarrow$ - famous prefabricated examples in the word Can be viewed through.

- A comparative analysis between prefabricated And conventional housing need to be done.

\section{几}

CONCLUSION \& INFERENCES

Fig 1. Research methodology for analysing prefabricated building systems.

\section{Literature review}

\subsection{Criteria for Selection of Prefabrication in India}

In India, the technology adopted for housing components should be of the order that, the technology of production and erection can be adjusted to suit the level of skills and handling facilities available under metropolitan, urban and rural conditions. The structural systems and components selected should ensure minimum material utilization with maximum structural merits. But, the component so designed are to be manufactured and erected by manual means 
within villages and small towns, semi mechanical techniques in towns and more or less fully mechanical operations in the metropolitan cities. In urban areas, the concentration of construction activity does not justify prefabrication. The answer is hybrid construction. In residential buildings, balcony projections can be provided along the partially precast joists, having an overhang carrying super imposed loads for balcony as specified in code IS: 875-1964, with addition to the self-load and the load due to railings. The main reinforcement for the overhang to be given at the top in the in-situ concrete attains sufficient strength. The savings achieved in practical implementations as compared to the conventional RCC slab is about $25 \%$. Mass housing targets can be met by replacing the conventional methods of building operation based on special and individual needs and accepting common denominator based on population needs. No single approach or solution is available which can satisfy the community at large. But desirable is to have a system which can provide choice for people and also appropriate techniques to meet the situation. The essence lies in the system approach in building methodology and not necessarily particular construction type or design. Adoption of any alternative technology on large scale needs a guaranteed market to function and this cannot be established unless the product is economical. Partial prefabrication is an approach towards the above operation under controlled conditions. The methodology for low cost housing has to be of intermediate type. Less sophisticated involving less capital investment. (Adhalkha and Puri, 2013)

\subsection{Prefabrication in Developing Countries}

Prefabrication technology has not transferred as easily when compared with other technologies because it is a production technology or knowledge based and not a consumption technology or product based. Technology transfer of prefabrication is not as pertinent to architects as it is to manufacturers of building products, but we are caretakers of culture in construction industry. In many cases we are asked to help with many of the transfers that are occurring by way of global practice or working for multi-national firms that are producing prefabricated components and entire buildings for India and elsewhere. Although transfers will continue to occur, especially in the area of prefabrication in building, we should be well aware of how the decisions of U.S. and western architects may have an effect on the ethical dilemmas regarding less developed countries' development and culture (Smith and Narayanamurthy, 2004).

\subsection{Prefabrication in India}

Prefabrication in India began with the emergence of the Hindustan Housing Factory. The company was developed by the first Prime Minister of India, Pandit Jawaharlal Nehru, as a solution to the housing crisis that resulted from the influx of refugees from West Pakistan in the 1950s. The Hindustan Housing Factory pioneered the production of pre-stressed concrete railway sleepers to replace dilapidated wooden sleepers on Indian Railways. The company changed its name shortly thereafter to reflect the diversity of its operations. It is now known as the Hindustan Prefab Limited or HPL. Located in Delhi, today the government- run company prefabricates primarily precast concrete for architectural and civil projects throughout greater India. When HPL began it was intended to produce low-income housing solutions for the deficit in India. Precast wall panels and frame members such as beams and columns provided muchneeded set of tools to erect quick structures for mass housing. The most difficult technology transfer obstacle for the HPL has been the cost of machinery and materials for production. Since the government could not recoup the return on investment for the factory through housing production, prefabrication from HPL began to service other markets including higher dollar civil and larger public and hotel buildings. The quality of construction is much higher when components are manufactured in a stable environment such as the factory. This is especially happens in India where nowadays prefabrication has become synonymous with western construction methods. Materials are used more effectively, and are safe from climatic damage, 
and can be easily reused in the material stream. Because of these benefits, a general consensus in India is to move prefabricated building systems beyond precast concrete for large-scale construction to additional market sectors including a resurgent interest in applying prefabrication technology to housing (Smith and Narayanamurthy, 2004).

\section{Ethical dilemma of Technology Transfer}

"Technology transfer use to affect the economy, and culture of both the transferring and the receiving nations. It opens too many ethical dilemmas." Prefabrication will continue to grow in India as the demand for fast affordable housing increases. However, technology transfer of prefabrication process, including materials and tools, affects the receiving country negatively. There are risks associated with the transfer of prefabrication technology. The host country may not have the infrastructure, the manufacturing and/or professional prowess to accept unconditionally, on other hand the negative impact can be social, environmental or economical. (Smith and Narayanamurthy, 2004).

\subsection{Transportation}

The shipping modules becomes cost prohibitive when they must travel more than 150 to 200 miles from factory to site. The industry generally recognizes 125 miles as the maximum practical distance modules should need to travel from factory to site. The Auroville Earth Institute in 1999 built a prototype-prefabricated house in New Delhi that showed advances in structural capacity during earthquakes. Initially envisioned as a disaster resistant and cost effective prototype, it was intended that the house would be precast anywhere and shipped by truck to a disaster location. Precast in Auroville, and then transported around 2,900 km to the site in New Delhi through a single lorry of 22.5 tons, the prototype was assembled in 66 hours by an 18 man team. The transportation cost alone was equal to the cost of manufacturing the model. This was economically unviable for developing country like India. The solution to low cost prefabricated housing must overcome the obstacle of shipping costs. Prefabricating regionally might better serve developing countries (Mittal, 2018).

\subsection{Human Rights}

Human rights issues are also of concern with regard to prefabrication technology transfer. As technology made way for mass production and assembly line manufacturing methods in the early part of the 20th century in the U.S., developing countries are using the same process to produce goods abroad today. Along with industrial manufacturing and economic benefits come labour challenges. Prefabrication presents problems: trading traditional handicraft construction jobs for automatic machines. Culture of localized building tradition which passed through generations is abruptly affected. Countries with a rich cultural background find it hard to accept drastic changes that involve a great deal of compromises in every field. This may directly affect technological advances, and in the construction field, it hinders the progress of prefabrication as a primary mode of construction. Prefab necessarily involves fewer labourers on site. It therefore renders helpless many households that depend on traditional methods of construction for their livelihood. With a literacy rate of only $61 \%$, the possibility of the construction industry labourers shifting occupation to an office or even an automated factory is bleak. The current labour market is a lot different from what it was the last decade. With an influx of the software industries (in the dotcom boom) and an opening for over a million jobs outsourced from outside India, the standard of living among the educated class is increasing.

\subsection{Schedule}

Modular construction allows for compression of the building schedule, because of the ability to overlap the module construction with site work similar to fast-track design-build construction. 
Some argue that technology has brought human kind many negative effects, including stressrelated diseases caused by people's inability to cope with the world that is moving too fast due to rapid technological progress. The schedule was measured from the beginning of design to the project completion. The time savings can be achieved by concurrent factory and on-site work, fewer weather delays, and less on-site material stock. For prefab projects, mostly design is more time intensive due to the added degree of coordination necessary to allow for module fabrication. Regarding construction schedule in less developed countries, specifically India, the concern is how to take advantage of cost reduction while still being able to employ individuals and maintain a cultural lifestyle that is unique to a society (Smith and Narayanamurthy, 2004).

\subsection{Precision}

One of the benefits of prefabrication technology is an increase in the quality of the products. Less developed countries such as India employ vernacular materials and methods in construction. The industry in India does not rely on precision, but the lack thereof in order to build everyday structures. Most members of local communities in India are equipped with knowledge of traditional construction. However, in India, a cultural divide between those that do and those who plan is emerging. This social class structural divide limits the ability for the populous to assimilate alternative methods of building quickly and adopt them into their culture of construction (Smith and Narayanamurthy, 2004).

\subsection{Climate and Vernacular}

One of the most significant influences on vernacular architecture is the macroclimate of the area in which the building is constructed. Buildings invariably perform well when built with regard to the local climate rather than a technological trend. The native environment and the construction materials which market do produce govern many aspects of prefab development. Vernacular, by definition, is sustainable, and will not exhaust local resources. For a country that has followed vernacular practices successfully for generations, like India, moving to a concept like prefab may not prove to be climatically as suitable. For example, in many hot regions of India, masonry walls that are heavy and dense conduct heat slowly and gradually. This process is called thermal lag, decreases peak cooling load in summer and peak heating load in winter. It results in a more comfortable home all year long that produces significant savings in energy. However, in India there are 6 distinct climate zones ranging from cold, dry to warm and wet. Therefore, India's architecture is varied in its use of materials with different fashion of construction while having cultural difference that cannot be generalized. Prefabrication as a technology transfer mode struggles should pursue in consideration these vernacular differences.

\section{Need of prefabrication}

According to the 2011 census, the housing stock in urban India stood at 78.48 million for 78.86 million urban households. Urbanization has resulted in people increasingly living in slums and has deteriorated the housing conditions of the economically weaker sections of the society.

Table 1. Housing Shortage In India

\begin{tabular}{|c|c|c|c|c|}
\hline & $\begin{array}{c}\text { Monthly Per Capita } \\
\text { Expenditure }\end{array}$ & $\begin{array}{c}\text { Estimated Number of } \\
\text { Households (2007) }\end{array}$ & $\begin{array}{c}\text { Housing Shortage In } \\
\text { Million (2007) }\end{array}$ & $\begin{array}{c}\text { Percentage } \\
\text { Shortage }\end{array}$ \\
\hline \hline EWS & $0-3,300$ & 21.81 & 21.78 & $99.9 \%$ \\
\hline LIG & $3,301-7,300$ & 27.89 & 2.89 & $10.5 \%$ \\
\hline MIG & $7,301-14,500$ & 16.92 & 0.04 & $0.2 \%$ \\
\hline HIG & 14,501 and above & 66.30 & 24.71 & $37.3 \%$ \\
\hline \multicolumn{2}{|r|}{ Total Shortage } & & & \\
\hline
\end{tabular}


Source: Report of the Technical Group (11th Five Year Plan: 2007-12) on Estimation Of Urban Housing Shortage

The housing percentage shortage in EWS is $99.9 \%$ which is double than the estimated number of households. Where as in HIG and MIG is so low $0.2 \%$ only. It highlights the mismatch between demand and supply of housing units. Further, the National Sample Survey Organization, 61st Round reports that the number of urban poor had increased by 4.4 million people, between 1993-94 to 2004-05.Therefore it is of vital importance that a new National Urban Housing and Habitat Policy analyses the ways and means of providing the 'Affordable Housing to All' with special emphasis on the EWS and LIG sectors (Teotia, 2014). The "National Urban Housing and Habitat Policy 2007" paper identifies clearly the need to provide sustainable affordable housing based on some of the following issues:

\subsection{Lack of Housing Stock}

At the advent of the 21st Century (2001), the housing stock in India presently is 50.95 million for 55.8 million urban households. Major segments of this housing stock was characterized by congestion and obsolescence Congestion is particularly acute in inner city slums and peripheral slums. According to the Census 2001,23.1\% of the urban population reside in slums. The quality of housing in slums is extremely poor. Slums are severely deficient even in the basic services such as potable water, sanitation, sewerage, Storm water drainage and solid waste disposal. (D’Souza, 2019)

\subsection{Increase in Urban Poverty}

Non-affordability of housing by economically weaker sections of society and low income families in urban areas is directly linked with the magnitude of poverty. The number of urban poor has risen by 4.4 million persons during 2004-05. Around one fourth of the country's total urban population of 80.7 million persons is below the poverty line. The urban poor constitute $26.7 \%$ of the total poor in the country. This fact that the number of urban poor has risen is in stark contrast with rural poverty, where both the total number of rural poor and its incidence with the rural population has fallen. According to the 2001 census, there is a 90\%deficiency in drinking water $26 \%$ in toilets and $23 \%$ in drainage. It is quite understandable that most of this shortage pertains to slums (Teotia, 2014).

\subsection{Need for Sustainable Habitat}

Development of sustainable habitat is closely related to the adoption of the regional planning, while preparing the Master Plans of towns/ cities, District plans and Regional/Sub-Regional Plans. It includes the maintenance of ecological balance in terms of a symbiotic perspective on rural and urban development while developing urban extensions of existing towns. The new Habitat Policy realizes the importance of small and medium urban towns. Which have potential for future urban growth. The new policy seeks to accelerate the development of such small and medium towns which can serve as generators of economic momentum while at the same time striving to reduce the rate of migration to existing large cities. The need for "Sustainable Affordable Housing" has been realized, efforts have been made to provide low income housing through policy changes and planning regulations applied in cities all over India. But a clear knowledge and understanding of sustainability is amiss in all previous and present initiatives. The pure need of addressing sustainability in the social integration, economic viability and prosperity, and sensitivity to climatic, social and community comfort has not yet been recognized (D’Souza, 2019). 


\section{Advantages and disadvantages of prefabrication}

\subsection{Advantages of Prefabrication}

There are many advantages of Prefabrication as compared to the construction building construction systems (Adlakha and Puri, 2013). They are summarized as below:

- Self-supporting ready-made components are used, so the need of shuttering, formwork and scaffolding is reduced greatly.

- Construction time is reduced and buildings are completed sooner, than conventionally built building, thus allowing earlier return of the capital invested.

- On-site construction and congestion is minimized.

- Quality control can be easier in a factory assembly line setting than a construction site.

- Prefabrication can be located where skilled labour is more readily available and costs of power, materials, space and labour are lower.

- Time spent in bad weather or hazardous environments at the construction site is minimized.

- Less waste may be generated and in a factory setting it may be easier to recycle it back into the manufacture process, like it will be less costly to recycle scrap metal generated in a metal fabrication shop than on the construction site.

- Moulds can be used several times.

\subsection{Disadvantages of Prefabrication}

There are also few disadvantages of Prefabrication as compared to the construction building construction systems (Adlakha and Puri, 2013). They are summarized as below:

- Careful handling of prefabricated components such as concrete panels or steel and glass panels is required.

- Attention has to be paid to the strength and corrosion-resistance of the joining of prefabricated sections to avoid failure of the joint.

- Similarly, leakages can take place at joints in prefabricated components.

- Transportation costs may be higher for voluminous prefabricated sections than for the materials of which they are manufactured, which may be packed more effectively.

- Large prefabricated sections require heavy-duty cranes and precision measurement and handling to place in position.

- Larger groups of buildings from the same type of prefabricated elements tend to look drab and monotonous.

- Local jobs are lost.

\section{Comparison between the prefabricated and conventional housing}

A comparison of a residential project for karanataka housing board at Kengiri, Karnataka, which had used the prefabricated system and Mahamedha co-operative housing society at Hapur, Uttar Pradesh (a North-Indian state), which had used the conventional construction system has been 
done. The images of the projects have been shown in Fig. 2 and comparative analysis has been summarized in the following Table No. 2 .
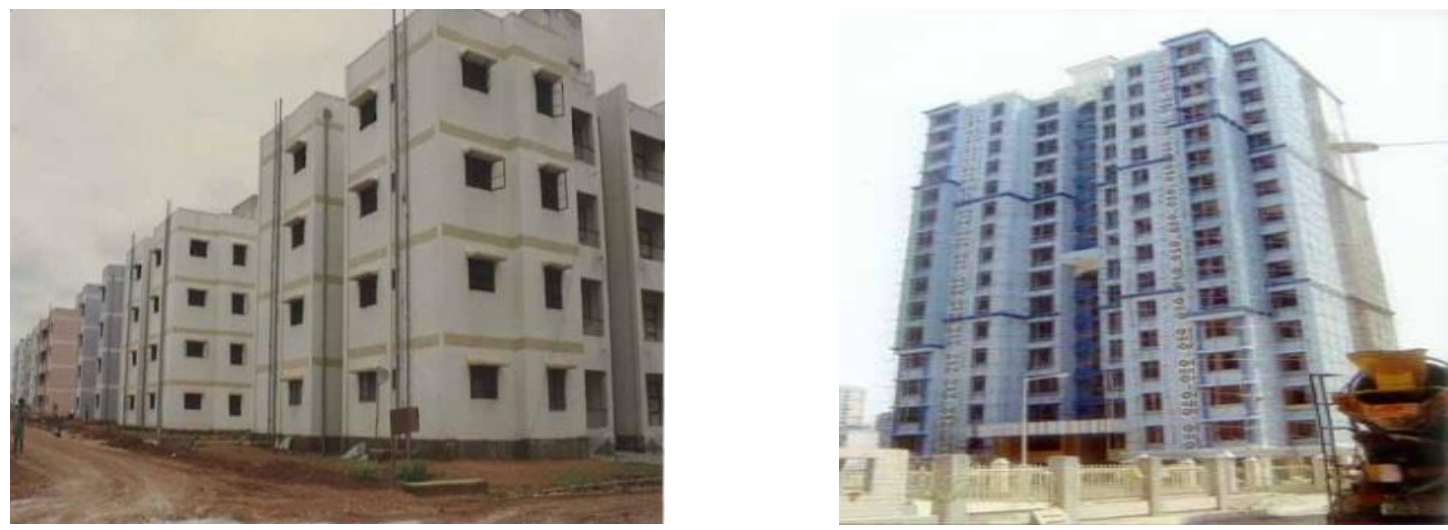

Fig. 2 Residential Project at Hapur and Residential Project at Kengiri

Table 2. Comparative analysis of Prefabricated and conventional construction system.

\begin{tabular}{|c|c|}
\hline Prefabrication & Conventional \\
\hline $\begin{array}{l}\text { Minimum no. of units required in a for } \\
\text { prefabricated construction to be economical is } \\
2500 .\end{array}$ & $\begin{array}{l}\text { If the no.of units in an housing is less than } 2500 \\
\text { then definitely conventional construction is } \\
\text { cheaper. }\end{array}$ \\
\hline 1. The cost reduces by $20 \%$ in super-structure. & $\begin{array}{l}\text { 1. The cost reduces by } 30-35 \% \text { in super-structure } \\
\text { if }>2500 \text {. }\end{array}$ \\
\hline 2. Time period for concrete to set - 1 day in factory. & 2. Time-period for concrete to set - 28 days. \\
\hline 3. Waste material used again. & 3. Waste material cannot be used. \\
\hline $\begin{array}{l}\text { 4. Labour force reduces and unskilled required is } \\
\text { very minimum. } 40 \% \text { labour reduced. } \\
\text { Site-(s:n-s)-(70-30) (erection) } \\
\text { Factory-(s:n-s)-(80-20) }\end{array}$ & $\begin{array}{l}\text { 4. Labour force required in comparison is very } \\
\text { high. } \\
\text { Site- (s:n-s)-(1:1.5) (erection) }\end{array}$ \\
\hline $\begin{array}{l}\text { 5. Cost-analysis- } \\
\text { - } \quad 20 \% \text { cost reduced from conventional style. } \\
\text { - Inclusive of labour, material, construction } \\
\text { and transportation. Cost of super- } \\
\text { structure only. } \\
\text { - Transportation cost is } 4.25 \% \text { if distance } \\
\text { between the site and factory is } 50 \mathrm{kms} \text {. } \\
\text { - Transportation cost increases is less } \\
\text { components have to be transported and } \\
\text { decreases if more components. } \\
\text { 20\% cost to be reduced total saving of } \\
\text { 162.5 Million only in R.C.C. in super- } \\
\text { structure. }\end{array}$ & $\begin{array}{l}\text { 5. Cost-analysis- } \\
\text { - No. of units }=2500 \\
\text { - } \quad \text { Average area of a unit=150 sqm } \\
\text { - Total area=3,75,000 sq.m } \\
\text { - } \quad \text { R. C. C. in super-structure include } \\
\text { - } \text { Aslumn+beam+slab } \\
\text { - } \quad \text { Cost of R.C.C= Rs. } 5500 / \mathrm{cu} . \mathrm{m} . \\
\text { - } \quad \text { Volume of R.C.C. }=150000 \mathrm{cu} . \mathrm{m} . \\
\text { - } \quad \text { Grade of concrete-M20 } \\
\text { - Total cost=Rs. } 82,50,00,000\end{array}$ \\
\hline 6. As $40 \%$ labour reduces, it is more economical. & 6. High labour charges as large no.of labours used \\
\hline $\begin{array}{l}\text { 7. } 1 \text { ndia being a country which has many festivals } \\
\text { and seasons so there is a lot of problem to find } \\
\text { labour during festivities. }\end{array}$ & $\begin{array}{l}\text { 7. Work is severely hampered during these } \\
\text { seasons. }\end{array}$ \\
\hline $\begin{array}{l}\text { 8. Employment rate reduces and for a country like } \\
\text { india where cheap and unskilled labour is available } \\
\text { in abundance due to poverty, it is a big set-back. }\end{array}$ & $\begin{array}{l}\text { 8. } 1 \text { t creates more employment } \\
\text { opportunities and is some relief to poverty. }\end{array}$ \\
\hline
\end{tabular}




\section{Comparison between different prefabricated residential housing}

A comparison of prefabricated residential projects for different housing boards in India has been done. A comparative analysis has been summarized in Table No. 3 .

Table 3. Legend title must be short and concise.

\begin{tabular}{|c|c|c|c|c|c|}
\hline $\begin{array}{c}\text { Examples of } \\
\text { Residential } \\
\text { Project }\end{array}$ & Images & $\begin{array}{c}\text { No. of } \\
\text { Units } \\
\text { Project Cost } \\
\text { (in Million Rs.) }\end{array}$ & $\begin{array}{c}\text { Average } \\
\text { Area of } \\
\text { Unit }\end{array}$ & $\begin{array}{c}\text { Completion } \\
\text { Time }\end{array}$ \\
\hline $\begin{array}{c}\text { Maharashtra } \\
\text { at Gousing Board } \\
\text { Mumbai }\end{array}$ \\
$\begin{array}{c}\text { Maharashtra } \\
\text { Housing Board } \\
\text { at Malad, } \\
\text { Mumbai }\end{array}$
\end{tabular}

\section{Case studies}

The following two case studies present the techniques and technological advancements in prefabricated building system.

\subsection{Turbo Tower, Chandigarh}

In the town of Mohali, a suburb just outside of Chandigarh in northwest of India, 10-storey tower was constructed in just 48-hours. The visionary behind this project, Harpal Singh of the infrastructure company Synergy Thrislington, told that it was all possible because the components have been manufactured already, water supply components, wiring, doors that can be pre-fitted, sanitation, air conditioning, ducts and everything is prefabricated. The components had been made from around 200 ton steel, and they were all prefabricated in a nearby factory before they were moved to the site on special transport trucks. The structure spread over 25,000 square meters and was completed in all respects including electrical installation in the time schedule. No bricks and sand had been used. The outer walls were double-skinned PUF panel. The cost was almost the same as of conventional construction. It saves a lot of time that goes into construction otherwise. Singh has gotten his project certified as earthquake and shock-proof by the Center for Industrial and Scientific Research. After just 6 hours, 3 floors had been constructed, and in 24 hours, nearly 7 stories had been completed. This ultra-fast construction had more than 80 per cent work pre-made and the rest happened on the site. The 
material used was manufactured in the previous two months in a nearby factory (Korones, 2012).

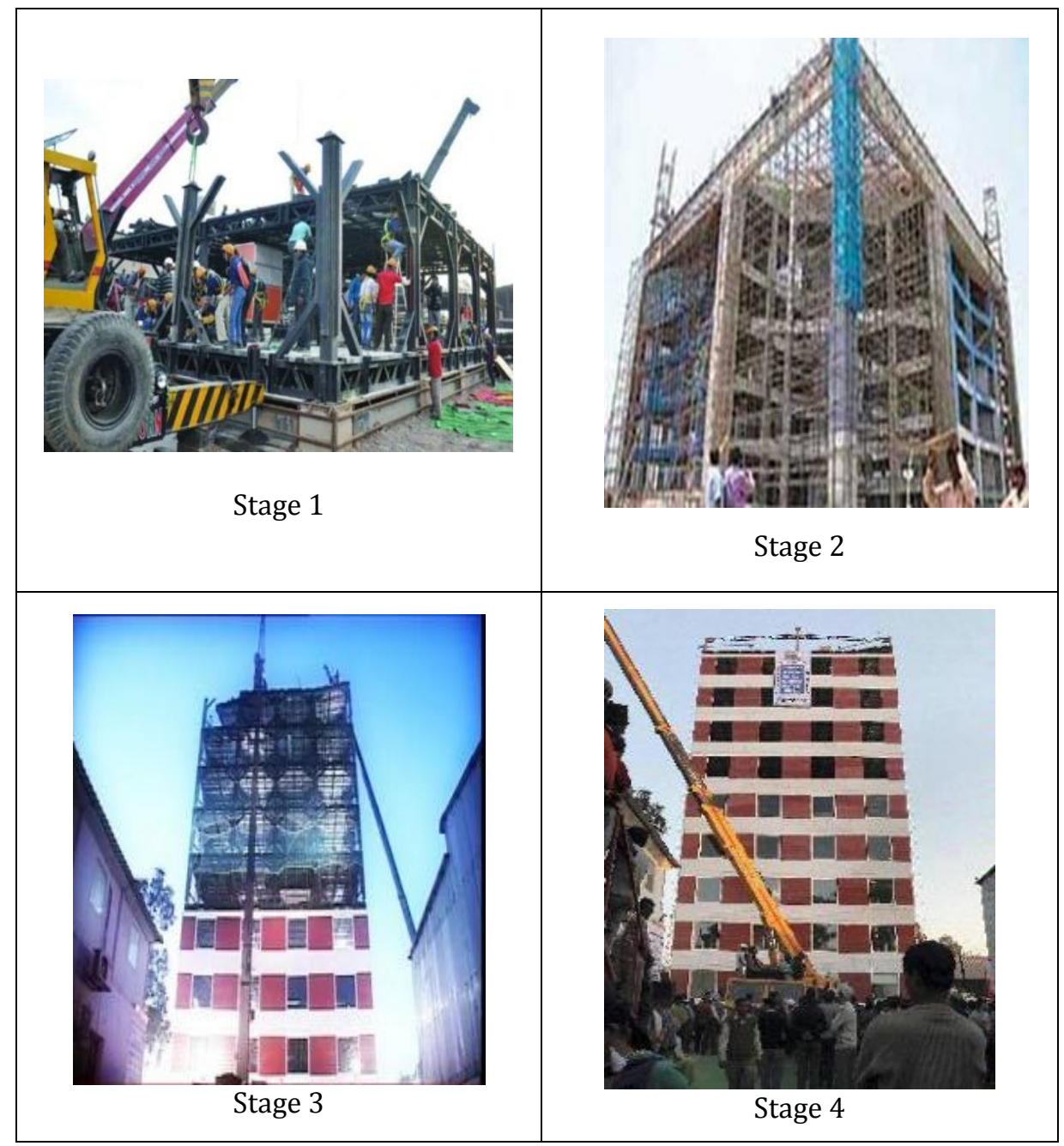

Fig 3. Different stages of prefabricated construction in Turbo Tower, Chandigarh, India.

\subsection{The Atlantic Yards, New York}

It is the tallest modular building in the world with 32 floors with height reaching 322 feets. Its architect - Shop broke down the monolithic size one expects to encounter street-side by composing the facade in a series of alternating bands of curtain glass and rusted-steel grid work. The modules/units used to construct the complex. All Modules are pre-assembled at the navy dockyards, transported here and then completed. Modules are picked directly from the truck and placed onto the building by a crane within the construction fence and set by a team of workers. Modules are bolted together work is undertaken to complete the connections of preinstalled building system components within each module. Each module has a floor level, but no ceiling. When the joining is done, it is kept in mind that the floor of the upper level module will act as a ceiling for the lower level. This further reduces the cost of construction. This tower is part of a $\$ 49$ billion, 22-acre Atlantic Yards project in Brooklyn. The 3 residential buildings contain a total of approximately 1500 units of residential housing. It is the first of the residential buildings to break ground, and at 32 floors and 363 units, the tallest modular building in the world. The stepwise collection of modules from pod links to the final floor groups which make the construction easier and faster. (Stott, 2014) 


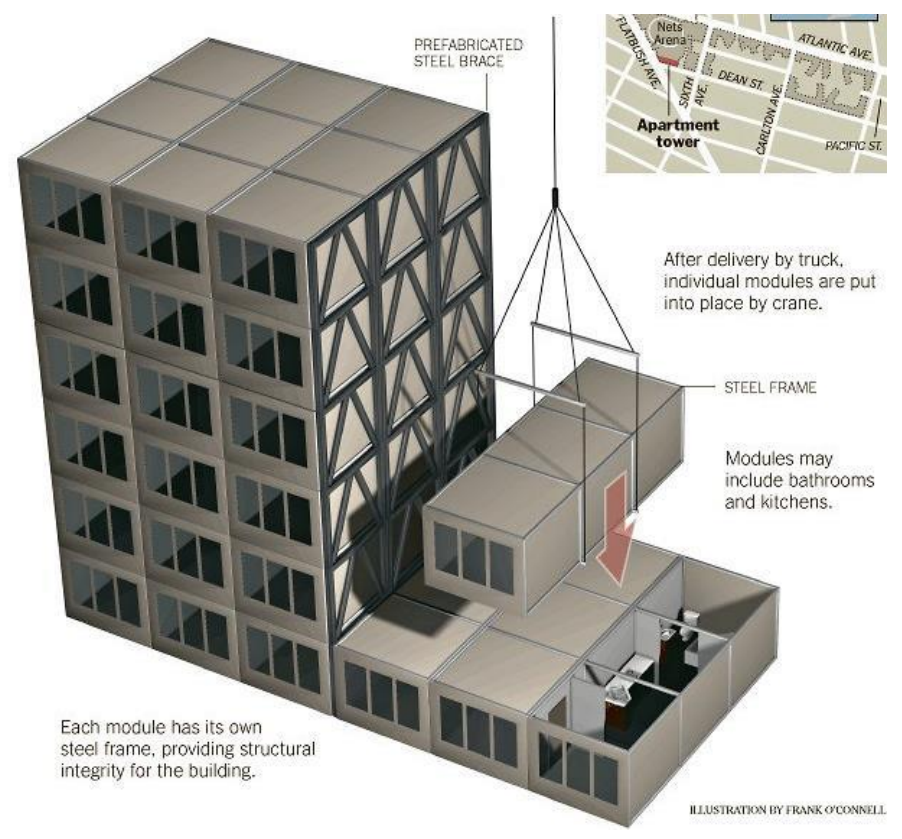

Fig 4. Volumetric modular construction in the Atlantic yard.

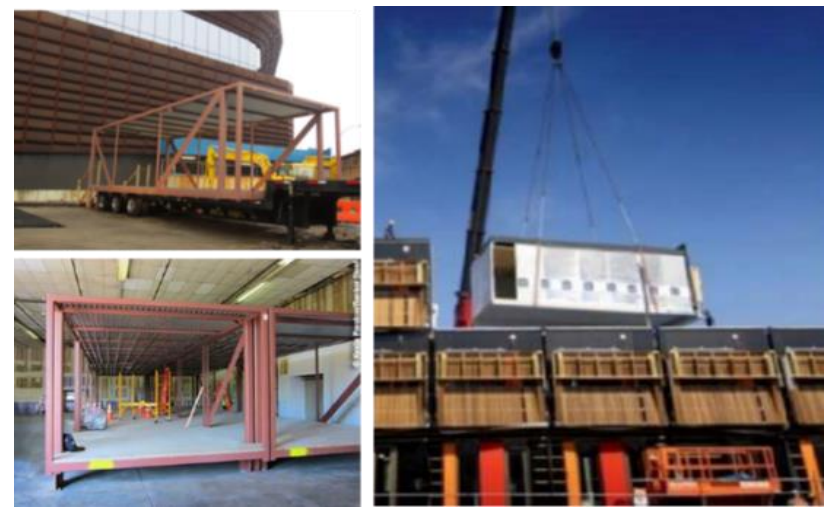

Fig 5. The Module and their placements through cranes.

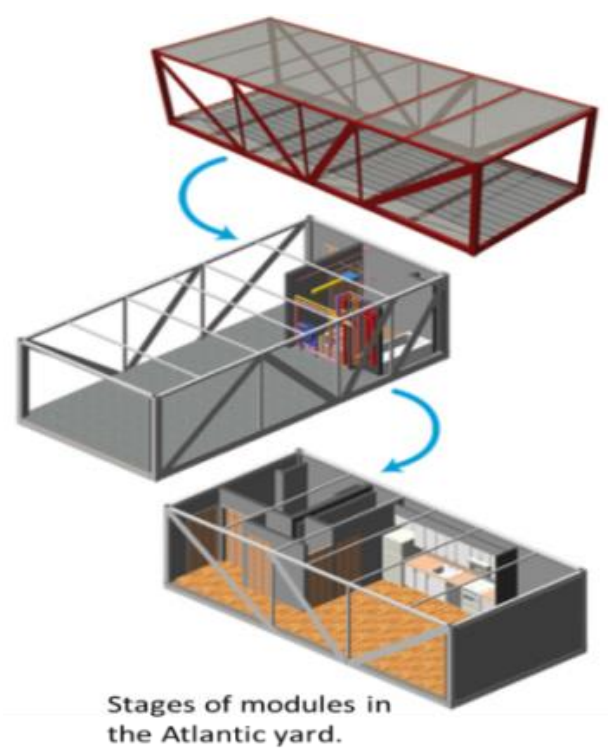

Fig 6. Stages of Module in the Atlantic Yard 


\section{Conclusions}

From the above study of various aspects of prefabrication, I can conclude that there exists a great potential for modular construction in the delivery of high-rise buildings. Production of same modules on a bigger scale can possibly create cost saving, for example in diverse housing developments. The size and weight of the modules to be used in a modular building need to be carefully considered with respect to transportation. According to the study typical module sizes for volumetric construction are 11 feet high, 12 to 16 feet wide, and 55 to 65 feet long. 200-mile distance is the maximum, from the site location is probably the most cost-efficient option with respect to transportation of the modules are the trucks.

Prefabrication has the capacity to drive down costs and improve the productivity of the construction industry. Targets can be met by replacing the conventional techniques of building operation based on some common base on the basis of surveys, no single solution is available which have the capacity to satisfy the community as a whole. But it will be desirable to have a system which can provide option to people and appropriate techniques to tackle different situations. To adopt any alternative technology needs a guaranteed market to function on large scale and this cannot be achieved unless the product is effective. Technology transfer of prefabrication is not as pertinent to architects as it is to manufacturers of building products, but we are caretakers industry. Sometimes architects are asked to help with many of the transfers that are occurring by way of global practice or working for multi-national firms that are producing prefabricated components and entire buildings for India and elsewhere. There lies interesting opportunities in urban city scale, where architect can provide different designing opportunities by using same building unit. The use of prefabrication merely offers an alternative route to procuring a building, which may offer opportunities for maximizing value for all concerned. Hence prefabrication is the solution for fast and time saving construction.

\section{References}

Adlakha P. K. \& Puri H. C. (2013), Prefabrication Building Methodologies for Low Cost Housing, Institution of Engineers Journal, AR, Vol. 84, 4-9, 2013.

Arieff, A. \& Burkhart, B. (2002). Prefab. Gibbs Smith Publisher, Utah, USA.

D'Souza R. (2019), Housing Poverty in Urban India: The Failures of Past and Current Strategies and the Need for a New Blueprint, ORF Occasional Paper No. 187, Observer Research Foundation, India.

Korones, S. (2012), In India, a 10-story tower built in just 48 hours, retrieved on Feb. 24, 2021 from https://www.zdnet.com/article/in-india-a-10-story-tower-built-in-just-48-hours/

Smith, R. E. \& Narayanamurthy (2004), Prefabrication in Developing Countries. from Edited book 'Without a Hitch: New directions in Prefabricated Architecture, University of Utah, USA.

Stott, R. (2014). Construction Halted on SHoP Architects' Atlantic Yards Housing Project, retrieved on Feb. 24, 2021 from https://www.archdaily.com/545230/construction-halted-on-shop-architects-atlanticyards-housing-project

Teotia M. K. (2014), Housing Poverty in Urbanizing India: Emerging Trends and Concerns, Proceedings of VIII ISA World Congress of Sociology, 13-19 July 2014, Yokohama, Japan.

Young, B. E., Seidu, R. D., Thayaparan, M., \& Appiah, K. J. (2020). Modular Construction Innovation in the UK: The Case of Residential Buildings, Proceedings of the International Conference on Industrial Engineering and Operations Management, March 10-12, 2020, Dubai, UAE. 